\title{
La mariguana en México: implicaciones biológicas y sociales en su legalización y regulación
}

\author{
Francisco Justiniano Velasco Arellanes', Erica Angelina Soto Mendívil' \\ I Universidad de Sonora, Campus Nogales, Sonora, México
}

\section{RESUMEN}

Introducción: en el presente trabajo se identifican tres vertientes relacionadas con el debate de la legalización y la regulación de la mariguana en México: 1) uso como tratamiento médico para enfermedades que no cuentan con una alternativa alópata en el mercado, 2) criminalización de la portación y uso en cantidades de autoconsumo y 3) industrialización con fines de lucro y de consumo recreativo. Objetivo: exponer la evidencia científica que se opone a la posibilidad de legalizar el uso de la mariguana en el sector "empresarial" o recreativo. Método: se realizaron búsquedas bibliográficas en bases de datos de revistas científicas. Resultados: la evidencia científica indica que la mariguana tiene efectos de índole biológico, psicológico y social. Discusión y conclusiones: la posibilidad de proporcionar a la población mexicana mariguana con fines recreativos puede tener importantes implicaciones sociales y de salud pública. En México no contamos con condiciones sanitarias y profesionales para contrarrestar las drogodependencias.

Palabras clave: mariguana, THC, legalización, regulación, ética.

\begin{abstract}
Introduction: this paper identify three aspects related to debate on the legalization and regulation of marijuana in Mexico: 1) Use as medical treatment for diseases that do not have an allopath alternative, 2) do not criminalize possession and use in quantities of self-consumption and 3) for-profit industrialization and recreational consumption. Objective: to present scientific evidence that opposes to possibility of legalizing the use of marijuana in "business" or recreational sector. Method: bibliographic searches were made in databases of scientific journals. Results: scientific evidence indicates that marijuana has biological, psychological and social effects. Discussion and conclusions: the possibility of providing to Mexican population with recreational marijuana represents a risk to public health. In Mexico we do not have sanitary and professional conditions to counteract drug dependence.
\end{abstract}

Keywords: marijuana, THC, legalization, regulation, ethics.

\section{Autor de correspondencia:}

Francisco Justiniano Velasco Arellanes. Av. UNISON núm. 343, col. Las Acacias, C.P. 84093, Nogales, Sonora, México. Correo electrónico: francisco.velasco@unison.mx

Recibido: 9 de mayo de 2017

Aceptado: 19 de febrero de 2018

doi: 10.28931/riiad.2018.1.05 


\section{INTRODUCCIÓN}

En México, la planta herbácea cannabis (mariguana) ha sido un tema de interés de algunos sectores de la sociedad. Reiteradamente, se ha propuesto que se debata su portación y uso de manera legal en el contexto del Congreso Federal. Los impulsores de la legalización son de diversa índole social; un sector, al que llamaremos de "políticas públicas", señala que las reprimendas armadas contra el narcotráfico fracasaron y que, lejos de disminuir la violencia y los riesgos de salud asociados con este problema, han favorecido el incremento de ganancias y el modus vivendi de los narcotraficantes. Así también, se sugiere que no hay políticas de rehabilitación que protejan a los usuarios de drogas y, por el contrario, se criminaliza al adicto y se le excluye de los servicios de salud. Estos y otros temas se han considerado en los foros de debate realizados en diferentes entidades del país (Secretaría de Gobernación [Segob], 2016).

Un segundo sector, que denominaremos "médico", asegura que el uso de la cannabis y sus derivados no debería tener trabas legales para tratar ciertas enfermedades como la epilepsia crónica, la artritis reumatoide y las secuelas de los tratamientos contra el cáncer, por mencionar algunas condiciones médicas relevantes en las que hace hincapié este sector.

Un tercer y último grupo, el "empresarial", sugiere que la legalización de la mariguana posibilitaría regular su distribución y calidad, obtener impuestos, fuentes de trabajo y fondos públicos para auspiciar centros especializados de rehabilitación para los consumidores.

No obstante, debido a las múltiples interpretaciones legales, económicas y de salud que implica un programa federal de legalización de la mariguana en México, es conveniente exponer desde las neurociencias y las ciencias sociales -y no sólo desde el mercado o la industria-, la viabilidad del proyecto de la legalización de la mariguana. El debate sobre el tema es reciente (Segob, 2016) y está en constante observación; al respecto, se requiere exponer y considerar diferentes argumentos.

Antes de comentar la evidencia científica que subyace a la posibilidad de legalizar la mariguana, señalamos tres vertientes argumentativas que se pueden identificar en los tres sectores anteriormente mencionados: 1) uso como tratamiento médico para enfermedades que no cuentan una alternativa alópata en el mercado, 2) criminalización de la portación y uso en cantidades de autoconsumo, y 3) industrialización con fines de lucro y de consumo recreativo o lúdico.

Adelantamos que el uso de la cannabis y sus derivados para fines médicos y la portación en cantidades permitidas para uso recreativo (Segob, 2016) tienen escasas objeciones. El presente manuscrito se concluyó cerca del inicio del proceso de minuta que emitió el Pleno del Senado en abril del año 2017, fecha en la que se dictaminó la necesidad de reformar la Ley General de Salud y el Código Penal Federal, a fin de facilitar el uso medicinal y científico de la mariguana. Finalmente, el 19 de junio se emitió el Decreto por el que se reforman y adicionan diversas disposiciones a la Ley General de Salud y el Código Penal Federal referentes a la aprobación del cultivo de la mariguana para uso medicinal y científico (Secretaría de Salud [SS], 2017).

En este trabajo consideramos pertinente que se haya emitido dicha disposición, ya que atiende a un sector específico que requería una vía legal para sus necesidades médicas y científicas. No obstante, la legalización y la regulación de la mariguana con objetivos de comercialización y de destino recreativo o lúdico (empresarial) conllevan una serie de consideraciones que se deberían tomar en cuenta por los riesgos sanitarios que pueden acarrear para la sociedad.

Por estas razones, en la presente revisión se expone evidencia científica que se contrapone a la posibilidad de legalizar el uso de la mariguana en el sector "empresarial" para fines recreativos o lúdicos, para ello se describen algunos aspectos neurobiológicos, psicológicos y sociales implicados en la producción, la comercialización y el uso de la mariguana.

\section{MÉTODO}

Para la presente revisión se realizaron búsquedas bibliográficas en las principales bases de revistas científicas electrónicas como ProQuest Dissertations, Psylnfo, OVID, Academic OneFile, EBM Reviews y Annual Reviews. De la misma forma, se consultaron instituciones nacionales e internacionales que emitieran reportes sobre epidemiologia de las adicciones. Como criterio para integrar las publicaciones en este trabajo, se consideraron aquellas que fueran clásicas en la caracterización de la mariguana, revisiones sistemáticas actuales, metaanálisis, ensayos clínicos, líderes en investigación y las que mostraran nuevos conocimientos en el área del efecto de la mariguana sobre la bioquímica de animales y el comportamiento humano. En total se consideraron 120 artículos para esta revisión. Se desarrollaron algunos apartados sobre evidencia y su relación con los mecanismos biológicos que explican los efectos de la mariguana. Por último, se vinculó la literatura con el contexto y las posibles consecuencias epidemiológicas que pudiese tener en nuestro país el uso de la mariguana con fines recreativos o lúdicos. 


\section{RESULTADOS}

\section{Características e influencia de la mariguana en la bioquímica cerebral}

La mariguana o cannabis es una herbácea de origen asiático que pertenece a la familia Cannabacea, incluye tres grupos: sativa, indica y ruderalis, la variedad más consumida en el mundo es la sativa (Villanueva, 2010); de ahora en adelante nos referiremos a ella por su acrónimo (Cs).

La Cs tiene propiedades psicoactivas que se caracterizan por alterar las funciones neurobiológicas de los individuos que la consumen. La intoxicación con Cs involucra a varios sistemas fisiológicos; los usuarios pueden presentar taquicardia, hipotermia, catalepsia, analgesia e incremento del apetito (Lupica, Riegel, \& Hoffman, 2004; Yamamoto et al., 2003). La Cs contiene más de 60 compuestos químicos (Yamamoto et al., 2003), de los cuales el principal es el $\Delta$ 9-tetrahidrocanabinol (delta-9-tetrahidrocanabinol), conocido como el tetrahidrocanabinol (THC). Este compuesto se absorbe rápidamente por vía pulmonar cuando se fuma; y vía intravenosa, mediante una sustancia vehículo (Justinova, Goldberg, Heishman, \& Tanda, 2005).

Los compuestos de la Cs actúan en el sistema endocannabinoide, un grupo de neuromoduladores lípidos importantes en el sistema nervioso. En la actualidad se conocen cinco endocanabinoides: 1) anandamida, 2) 2-araquidinoilglicerol, 3) éter de noladina, 4) virodamina y 5) $\mathrm{N}$-araquidonoildopamina (Cota, Tschöp, Horvath, \& Levine, 2006). El sistema endocanabinoide, por cuestiones evolutivas, enlaza sus cinco neuromoduladores lípidos (ligandos) a receptores CB1 y CB2; pero son los compuestos de la Cs los que, de manera substituta, se enlazan ocupando los receptores CB1 y CB2. Para evitar confusiones al respecto, es necesario hacer una distinción entre los compuestos de la Cs, llamados exocanabinoides, y los endocanabinoides, que produce el organismo (Villanueva, 2010).

Los receptores del sistema endocannabinoide que se conocen como CB1 (Matsuda, Lolait, Brownstein, Young, \& Bonner, 1990) y CB2 (Munro, Thomas, \& Abu-Shaar, 1993) son miembros de un dominio de siete segmentos transmembrana acoplados a la pareja de proteínas inhibitorias Gi y Go. (Pertwee, 2006; Piomelli, 2003). El receptor CB1 es el más abundante y se encuentra implicado en todos los tipos de sinapsis del sistema nervioso (Freund, Katona, \& Piomelli, 2003; Pertwee, 1997); se ubica, principalmente, en las terminales nerviosas en las que median la actividad de otras neuromoléculas como el GABA, el glutamato, la dopamina y la serotonina (Lupica et al., 2004).

El receptor CB1 es considerado un mensajero retrogrado porque es liberado por neuronas postsinápticas e inhibe los procesos de liberación de otros neurotransmisores presinápticos como el GABA, el glutamato, la do- pamina y la serotonina (Citri \& Malenka, 2008; Lupica et al., 2004). Asimismo, es importante en los mecanismos moleculares que subyacen a los cambios transitorios y de larga duración de la fuerza de la sinapsis (Citri \& Malenka, 2008; Lupica et al., 2004; Malinow, Mainen, \& Hayashi, 2000). Los cambios en la transmisión sináptica ocurren en varias áreas cerebrales comunes al circuito de las recompensas y las drogas de abuso como el núcleo accumbens, la corteza prefrontal, el área tegmental ventral (ATV), el globo pálido ventral y el hipocampo (Lupica et al., 2004).

La alteración del sistema endocanabinoide, a través de la ocupación del receptor CB1, tiene un papel importante en la manifestación de varios desórdenes cerebrales; se ha encontrado que el uso de la mariguana en etapas tempranas de la vida, como la adolescencia, es un disparador de trastornos esquizofrénicos (Katona \& Freund, 2008) y un desestabilizador para que emerja la anhedonia o incapacidad para experimentar placer o interés por las actividades cotidianas (Garfield, Lubman, \& Yücel, 2014; Lubman, Cheetham, \& Yücel, 2015).

En usuarios asiduos (heavy users) se ha encontrado que es un iniciador de la depresión (Lev-Ran et al., 2013); además, reduce la competencia creativa debido a que afecta la adquisición de nuevos conocimientos (Kowal et al., 2015) y altera de forma severa la estructura del sistema nervioso, en particular el área medial temporal implicada en diferentes procesos de memoria declarativa y de largo plazo (Lorenzetti et al., 2015).

En un estudio reciente de Hebert-Chatelain et al. (2016) se presentó evidencia de que el impedimento en memoria de los usuarios de Cs puede ser explicado como una cascada de eventos, en la cual las mitocondrias ocupan un lugar importante. En términos generales, los cannabinoides exógenos inducen una disminución de la actividad de las mitocondrias, a través de la proteína $\mathrm{G}$ ai de los receptores cerebrales mitocondriales CB1; a su vez estos desencadenan la inhibición de la actividad de SAC, una reducción de los niveles del AMP cíclico y un decremento de la fosforilación dependiente de PKA (Proteína quinasa dependiente de CAMP) de proteínas OXPHOS, entre las cuales la subunidad I del complejo NDUFS2 desempeña un papel funcional importante. Los autores señalaron que, además de sus efectos amnésicos, a través de la alteración de las mitocondrias, la Cs también puede participar en la patogénesis de enfermedades neurológicas y psiquiátricas.

El receptor CB2 y su ligando endocannabinoide, aun cuando se encuentra en menor cantidad, están relacionados con la liberación de citocinas y éstas, a su vez, con la actividad de las células inmunes (Pertwee, 2006). Las citocinas son una familia de proteínas péptidas que median en la comunicación intercelular, inducen la acti- 
vación de receptores específicos de membrana, están implicadas en la proliferación y la diferenciación celular, así como en el crecimiento y la secreción de inmunoglobulinas. La relación entre el sistema endocannabonide y las citocinas es central para entender por qué los tratamientos basados en exocannabinoides, como el THC, palian los síntomas de algunas enfermedades neurológicas (Katona \& Freund, 2008), pero también para comprender cómo la modificación del sistema endocannabinoide por consumo de mariguana de manera crónica, se asocia con problemas de pérdida de la capacidad de retención, desorientación espacial y emergencia de la esquizofrenia (Gerdeman \& Lovinger, 2003). A través de la estrecha relación que tiene el receptor CB2 con las células inmunes, se puede explicar, además, el origen de algunos cánceres o de la infertilidad (Ji, Grossmann, \& Ji, 1998).

El hecho de que los compuestos del cannabis y sus derivados actúen sobre los receptores CB1 y CB2 es muy importante, porque pueden modificar las estructuras celulares, a través de las proteínas G's y las citocinas. Los estudios indicaron que el sistema endocannabinoide está implicado en la reestructuración del patrón de actividad celular y en la plasticidad sináptica a largo plazo (Katona \& Freund, 2008; Lupica et al., 2004; Pertwee, 2006).

Todavía no se conocen todas las posibles alteraciones estructurales que provoca el uso de la mariguana y sus derivados en el sistema endocanabinoide, pero se sabe que los receptores CB1 y CB2 se vuelven incapaces de unirse a los ligandos que les corresponden (anandamida, 2-araquidinoilglicerol, éter de noladina, virodamina y $\mathrm{N}$-araquidonoildopamina); esto tiene repercusiones porque trastoca las respuestas normales y señales consecutivas de las células. De la misma forma, dichos receptores (CB1 y CB2) pueden no ser expresados en la superficie celular (Gerdeman \& Lovinger, 2003; Katona \& Freund, 2008). La Cs modifica toda la fisicoquímica del sistema endocanabinoide, por lo que sus repercusiones en la salud y el comportamiento de los usuarios es un área en constante investigación.

\section{Efectos de la mariguana y derivados en el compor- tamiento de animales y humanos}

En modelos animales se han evaluado algunas moléculas sintéticas que se alojan en los receptores endocannabinoides; se ha encontrado que al afectar el sistema endocannabinoide, se modifica la fuerza o eficacia de la transmisión de las sinapsis ya existentes, es decir que las moléculas sintéticas modifican la actividad neuronal o plasticidad (Iversen, 2003). Se identificó que un agonista sintético WIN55-212-2, que actúa en el receptor CB1, aplicado de forma directa en el área tegmental ventral (ATV) puede reducir eléctricamente la corriente posi- náptica inhibitoria evocada, la cual también es mediada por la activación de receptores GABA (Szabo, Siemes, \& Wallmichrath, 2002). El GABA, a su vez, es el regulador natural de la dopamina y se sabe que este neurotransmisor está relacionado con la activación de los opiáceos endógenos (Balleine, 2005; Yeomans \& Gray, 2002).

La actividad de la dopamina se vincula con alteraciones en la eficiencia para identificar estímulos en situaciones cambiantes (Berridge \& Robinson, 1998), y esta cadena de procesos bioquímicos finalmente impacta en el proceso neurológico del aprendizaje, lo que genera problemas de retención (Sullivan, 2000).

Las vías de acción del sistema endocannabinoide con otros sistemas de neurotransmisores es compleja, pero el papel de mensajero retrógrado que tiene el ligando natural del receptor CB1 puede explicar por qué el THC que proviene de la mariguana inhibe también los procesos de las neuronas presinápticas. Asimismo, puede explicar cómo los compuestos de la mariguana generan depresión a largo plazo por la fuerza de la sinapsis. Este último mecanismo ofrece la explicación de los problemas de memoria y de ubicación espacial en modelos animales (Deadwyler \& Hampson, 2008; Kruk-Slomka \& Biala, 2016; Marsicano \& Lafenêtre, 2009; Robinson et al., 2007) y en estudios realizados con humanos, en los cuales se ha mostrado que los usuarios con altos niveles de consumo de mariguana tienen problemas de memoria a largo plazo, lo que dificulta la adquisición de nuevos conocimientos (Sullivan, 2000).

El CB1 y su relación con otros receptores es complicada, pero es un hecho que está implicado en la trasmisión en la sinapsis cortico-estriada, importante en funciones cognitivas de alto orden. Su vinculación es tan significativa y múltiple, que se ha encontrado asociado con receptores poco conocidos como la Adenosina A2A (Tebano, Martire, \& Popoli, 2012). Estas relaciones complejas e importantes no son extrañas, pues el sistema nervioso opera como una condición biológica necesaria para la emergencia de funciones consideradas de alto orden (Bunge, 1979).

\section{Vulnerabilidad del sistema nervioso de los jóvenes al uso de la mariguana}

El uso de drogas es particularmente riesgoso en jóvenes en desarrollo, al respecto Hurd, Michaelides, Miller y Jutras-Aswad (2013) destacaron la vulnerabilidad del cerebro adolescente respecto del consumo de drogas, así como los riesgos asociados con un uso extendido de mariguana entre los jóvenes, debido a políticas permisivas y a la disminución de la percepción de riesgo entre la población.

Zammit et al. (2008) realizaron una revisión sistemática de 13 estudios longitudinales provenientes de 10 bases de datos relevantes, con el fin de analizar si el consumo de 
cannabis afecta la remisión de trastornos psicóticos. Los autores encontraron que en pacientes que ya presentan esta enfermedad, el consumo de cannabis se asocia con el aumento de las recaídas, los reingresos a hospitalización y la falta de adherencia al tratamiento. En otra revisión sistemática con 35 estudios, realizada por Moore et al. (2007), se analizó el consumo de cannabis y la aparición trastornos psiquiátricos; se encontró un aumento del riesgo de cualquier trastorno psicótico en individuos que han consumido cannabis alguna vez. Los resultados fueron consistentes con un efecto dosis-respuesta y se presentó con mayor riesgo en personas que consumieron cannabis con mayor frecuencia. La evidencia es consistente con la visión de que el cannabis aumenta el riesgo de que emerjan trastornos psicóticos.

En contraste, un estudio longitudinal de Degenhardt y Hall (2002) sugirió que es poco probable que el consumo de cannabis provoque psicosis en personas que no han desarrollado la enfermedad en etapas de desarrollo adulto. No obstante, los autores señalaron que es más consistente la hipótesis de que el consumo de cannabis puede precipitar la psicosis en personas vulnerables y aumentar el riesgo de recaída hospitalaria entre los que ya han desarrollado la enfermedad; además, afirmaron, es más probable que la mariguana conduzca a la dependencia en personas con esquizofrenia. De acuerdo con esta hipótesis, Hall, Degenhardt y Teesson (2004), junto con Degenhardt y Hall (2006), escribieron que en estudios longitudinales se demuestra que el consumo de cannabis puede precipitar la esquizofrenia en individuos vulnerables y que también exacerba la psicosis.

En coincidencia, Semple McIntosh y Lawrie (2005) indicaron que la cannabis aumenta el riesgo de presentar trastornos psicóticos. En su estudio encontraron que los síntomas se incrementan como efecto de la dosis de cannabis en grupos vulnerables (con historia psicótica familiar) y en personas cuyo inicio del consumo se dio en la adolescencia. Estos resultados son evidentes cuando se contrastan grupos de consumidores de cannabis que ya tienen una historia de brote psicótica con otros que no la han presentado.

Van Os et al. (2002) siguieron a dos grupos de usuarios durante tres años; encontraron que la historia de consumo de cannabis incrementa el riesgo de presentar síntomas psicóticos incluso en individuos con una vida con ausencia de psicosis. Asimismo, detectaron una fuerte interacción acumulada entre el consumo de cannabis y la vulnerabilidad previa a presentar trastornos psicóticos. Large, Sharma, Compton, Slade y Nielssen (2011) realizaron un metaanálisis de artículos, en los cuales se comparó la edad de inicio de la psicosis entre pacientes que utilizaron substancias y no usuarios. Se consultaron 443 artículos con este criterio, de los cuales se recabaron 83 publicaciones con revisión por pares; se identificó que la edad de inicio de la psicosis en los usuarios de mariguana se presenta 2.7 años antes que en los no usuarios. Las diferencias presentadas por los usuarios de cannabis y el grupo de los no usuarios de sustancias confirmaron una asociación entre el uso de cannabis y una menor edad en el inicio de la psicosis.

Otros trastornos como la depresión y la ansiedad también fueron analizados para evaluar si se presentan por el uso del cannabis; Degenhardt et al. (2013) indicaron que si bien no hay asociación consistente entre el consumo de cannabis y la depresión en adultos jóvenes, la utilización regular de cannabis por los adolescentes se encuentra consistentemente asociada con la ansiedad. En el mismo sentido, Degenhardt, Hall y Lynskey (2003) encontraron una modesta asociación entre el uso frecuente de cannabis y la presencia de depresión.

En un estudio con 1,601 estudiantes de entre 14 y 15 años de edad -a los cuales se les dio seguimiento por siete años-, se encontró que hay cinco veces más posibilidades de que las mujeres presenten depresión y ansiedad (Patton et al, 2002). También se comprobó que los usuarios más frecuentes (que fuman diario) presentan más riesgo de presentar depresión y ansiedad, en comparación con los que fuman una vez por semana o menos.

En una investigación, cuyo objetivo fue evaluar un modelo de usuarios de mariguana, Simons, Clarke, Simons y Spelman (2016) detectaron problemas de motivación y la manifestación de obstáculos para el cambio. La muestra fue de estudiantes de entre 18 y 25 años que utilizaron mariguana en los últimos seis meses; se utilizó un modelo de ecuación estructural donde se analizaron los motivos para consumir mariguana. Se encontró que los jóvenes que usan esta droga presentan menor motivación para el cambio y menor interés por cumplir metas personales.

Como ya hemos señalado, los adolescentes que usan mariguana presentan déficits cognitivos relacionados con el consumo, incluso seis semanas después de la abstinencia, en particular en los ámbitos de aprendizaje y memoria. Hay que agregar, además, que los adolescentes son más afectados por el uso de la mariguana que los adultos (Tapert, Schweinsburg, \& Brown, 2008).

\section{Problemas cognitivos, toma de decisiones}

Alameda, Paino y Mogedas (2012) compararon a 41 consumidores y 41 no consumidores de mariguana, para identificar alteraciones en el proceso de toma de decisiones de los consumidores. Se halló que los usuarios muestran más dificultades en la toma de decisiones en una prueba de juego, en comparación con los no consumidores. 
En un estudio de Vélez, Borja y Ostrosky-Solís (2010), en el que se evaluó la toma de decisiones en una población consumidora de mariguana, comparada con grupo control, se encontró que los consumidores de mariguana dan mayor importancia a situaciones o experiencias que implican gratificación inmediata, ignorando las posibles consecuencias adversas que sus decisiones pueden tener. Este resultado puede indicar cierta tendencia a la premura o impulsividad en los usuarios de mariguana.

Bolla, Brown, Eldreth, Tate y Cadet (2002) reportaron un decremento en el funcionamiento de la memoria, la velocidad psicomotora y la destreza manual en usuarios de mariguana. Estos resultados no resuelven la pregunta si la abstinencia favorece la recuperación de estos déficits, tampoco si el incremento de la frecuencia y la cantidad de mariguana incrementa los problemas de memoria.

En una revisión sistemática, Beverido (2010) señaló que los estudios indican que si se consumen drogas en etapas de desarrollo temprano (adolescencia), puede haber consecuencias profundas y de larga duración. El uso prolongado de dosis altas de THC puede conducir a un estado de pasividad e indiferencia (síndrome anhedonia), y como ya se comentó anteriormente, puede desencadenar trastornos psicóticos y agravar los trastornos esquizofrénicos.

En una revisión sistemática se demostró que las investigaciones fortalecen la idea de que la mariguana tiene efectos severos en la neurocognición; se ha mostrado que el uso de cannabis afecta el aprendizaje, provoca una disminución de la atención y la concentración e impacta el razonamiento abstracto y la memoria episódica. Las funciones de memoria principalmente se alteran durante la intoxicación aguda por cannabis; pero permanece en gran medida intacta, tanto en consumidores adultos como en adolescentes, que transitan por una abstinencia reciente. Esto parece indicar que después de cesar el consumo de mariguana puede haber recuperación de estas funciones (Crane, Schuster, Fusar-Poli, \& González, 2012).

Fried, Watkinson, James y Gray (2002), con el objetivo de evaluar inteligencia (Intelligenz-Quotient, IQ), identificaron diferencias en el IQ entre usuarios y no usuarios de mariguana (poblaciones de entre 17 y 20 años). Se reportaron efectos negativos en las medidas de IQ en sujetos que fumaron mariguana más de cinco veces en una semana, no obstante, el uso de esta sustancia no presentó efectos negativos de largo plazo en la inteligencia global. En un estudio longitudinal realizado por Hanson et al. (2010) se encontró que adolescentes que usaron mariguana, en las primeras tres semanas de abstinencia seguían presentando disminución en el aprendizaje verbal, en la memoria de trabajo verbal y en la precisión de la atención, en comparación con los no usuarios. Los resultados indicaron que la mariguana, incluso después de la abstinencia deja anoma- lías en el córtex prefrontal, subcortical e hipocampal. Otro estudio realizado por Meier et al. (2012) obtuvo los mismos resultados que el estudio anterior: los usuarios de mariguana presentan problemas de cognición y concentración; y, aunque se suspenda el uso de la sustancia, no recuperan totalmente el funcionamiento neuropsicológico.

En una investigación realizada por Pope, Gruber, Hudson, Huestis, \& Yurgelum-Todd (2001) se encontró que en usuarios de mariguana se observa disminuida la capacidad de recordar listas de palabras. Se indicó que algunos déficits cognitivos aparecen a los siete días del uso intensivo de mariguana, aunque estos pueden ser reversibles.

Mena et al. (2013) indicaron que las pruebas neuropsicológicas muestran en los consumidores de mariguana menores habilidades cognitivas asociadas con el proceso de aprendizaje, tales como atención, concentración, jerarquización, integración viso- espacial, retención inmediata y memoria visual. Las diferencias entre grupos de consumidores y no consumidores son estadísticamente significativas.

La relación funcional entre las distintas regiones cerebrales y las funciones neuropsicológicas afectadas por el consumo de cannabis sugieren la existencia de una desregulación de los circuitos que conectan la corteza prefrontal, el hipocampo y el núcleo estriado, lo que deteriora la capacidad de contextualizar la información que alimenta los sistemas de pensamiento y predicción (Verdejo-García, 2011).

En otro estudio, Filbey et al. (2014) usaron diferentes tipos de mediciones cerebrales en un grupo de consumidores crónicos de mariguana. Los resultados indicaron que el consumo crónico de mariguana está asociado con el deterioro de procesos neuroadaptativos (procesos moleculares y estructurales en el sistema nervioso) y que a más temprana edad de inicio y mayor consumo de mariguana, mayor deterioro.

\section{Accidentes de tránsito y uso de mariguana}

El estudio de Asbridge, Hayden y Cartwringht (2012) consistió en determinar que el consumo agudo de cannabis incrementa el riesgo de sufrir accidentes vehiculares. A través de la revisión de autoinformes y estudios toxicológicos de conductores que habían sufrido accidentes vehiculares, se analizó un grupo control de conductores que no demostraron el consumo y otro grupo que tuvo resultados positivos en el uso de cannabis. Se encontró que bajo la influencia de esta droga, los conductores tienen un riesgo mayor de sufrir un accidente, en especial con consecuencias fatales (Odds Ratio 1.92), comparado con quienes no conducen bajo el efecto de la sustancia. Otro estudio de Belrness y Porath-Waller (2015) refirió que el riesgo de accidentes después del consumo de mariguana no se limita al conductor sino a los que deciden viajar con ellos. El riesgo se incrementa significativamente 
cuando el consumo de cannabis se combina con el uso de alcohol.

Brady y Guohua (2014) realizaron un análisis del censo de accidentes de tránsito, a partir de la base de datos del Sistema Nacional de Seguridad de Tránsito de Washington, en un periodo de 1999-2010. Los resultados mostraron que el consumo de drogas en los últimos años en conductores accidentados se ha incrementado, por lo que el riesgo de choque se relaciona seriamente con el consumo de sustancias psicoactivas. Fue, en particular, evidente el aumento de la prevalencia del consumo de estupefacientes y cannabis en accidentes fatales que involucraron personas fallecidas. En el mismo sentido, Crancer y Crancer (2010) analizaron los datos de muertes de pasajeros en algún accidente de tránsito asociado con el consumo de mariguana. Se encontró un aumento en el riesgo de morir o de provocar la muerte de una tercera persona, en 8.3\%. En el estado de California se registran 840 defunciones por año bajo el contexto de uso de sustancias, $20 \%$ más de las que se registraban con anterioridad a la permisividad del uso de la mariguana.

Laumon, Gadegbeku, Martin y Biecheler (2005) realizaron un estudio en donde se compararon casos de personas involucradas en accidentes y de conductores no involucrados en accidentes: se consideraron 6,766 casos de conductores culpables de algún accidente y 3,006 de otros conductores tomados aleatoriamente. Se midieron concentraciones séricas de alcohol y mariguana por encima de 1ng/ml.; 681 conductores dieron positivo para mariguana (8.8\% de casos involucrados en accidentes y $2.8 \%$ de los controles). Se detectaron también 285 con concentraciones ilegales de alcohol, variable que fue controlada. La detección sérica de cannabis se asoció con un mayor riesgo de ser responsable de algún accidente de tránsito fatal, pues el riesgo aumenta 2.8 veces si las concentraciones séricas se elevan por encima de $5 \mathrm{mg}$. La prevalencia de mariguana se estimó en $2.7 \%$ de los conductores, de los cuales hasta 3.5\% se podría ver involucrado en algún accidente fatal. En otro estudio realizado en Colorado se examinó la proporción de accidentes fatales entre 1994 y 2011 que dieron positivo en mariguana y en consumo de alcohol. Se encontró que a partir de 2009, cuando la mariguana para uso médico se empezó a comercializar, aumentó el número de conductores que sufrieron accidentes fatales y resultaron positivos en el consumo de mariguana (Salomonsen-Sautel, Min, Sakaia, Thurstone, \& Hopfer, 2014).

\section{La legalización de la mariguana o sus derivados, dos condiciones justificables}

\section{Uso médico terapéutico}

En el mundo no se tiene un registro confiable sobre el número de usuarios de Cs o sus derivados para fines médi- cos, porque su consumo puede ser transitorio o estar sujeto a confidencialidad médica. En países como Holanda, Inglaterra, Canadá, Nueva Zelanda y Estados Unidos, se legalizó el uso de sustancias sintéticas y derivadas de la mariguana para uso médico, el THC es el compuesto más común en los medicamentos (Whiting et al., 2015). Los padecimientos que se han tratado con algún componente de la mariguana son SIDA (Fogarty et al., 2007), esclerosis múltiple (Nielsen et al., 2018), vómito y náusea inducidos por la quimioterapia (Cotter, 2009), dolor crónico (Beaulieu, Boulanger, Desroches, \& Clark, 2016), inflamación, algunos tipos de cáncer (Birdsall, Birdsall, \& Tims, 2016) y reumatismo (Leleu-Chavain, Desreumaux, Chavatte, \& Millet, 2014), por mencionar algunos.

En estudios en los que se ha comparado el consumo de Cs y THC para uso médico, se ha hallado que usar de manera directa los componentes de la mariguana propicia efectos similares que los generados por sus derivados con patente farmacológica que contienen $\mathrm{TCH}$; sin embargo, no se han estudiado con precisión los efectos secundarios y colaterales por inhalación de humo, la dependencia y las emociones que pudiesen tener los pacientes que consumen directamente los componentes de la CS (Cotter, 2009; Hart et al., 2002).

Lo que podemos señalar es que el uso medicinal de la Cs o sus derivados cuenta con evidencia científica suficiente para poder justificar su aplicación medicinal por cuerpos médicos dentro de las instituciones de salud, incluso se han descrito las competencias profesionales para evaluar su rechazo cuando se encuentran efectos adversos. Por estas razones, el uso clínico de los derivados de $\mathrm{Cs}$, la condicionan, no la justifican para fines recreativos o lúdicos. Los derivados sintéticos de Cs para tratamiento clínico de enfermedades como la artritis reumatoide, el cáncer y la esclerosis múltiple se regulan desde instituciones como la Food and Drug Administration (FDA), en Estados Unidos, y la Comisión Federal para la Protección contra Riesgos Sanitarios (Cofepris), en México. No se requiere aludir a una necesidad clínica para legalizar de manera indiscriminada el uso de la Cs, ya que el desarrollo farmacológico cuenta con mecanismos de regulación legales, éticos y confidenciales para este sector.

De esta forma, el tema de la legalización y regulación de la Cs para fines medicinales no debe considerarse como un tema a debatir, ni debe confundirse con la legalización para uso recreativo, es de hecho viable que se use la Cs en el tratamiento de las enfermedades y que se mejore la calidad de vida de los enfermos. Es importante recalcar que la aplicación médica de la Cs, contrario a lo que piensa la mayoría de personas, se realiza aislando o sintetizando sus componentes, no se realiza consumiéndola en su estado "natural". 
El uso de los derivados de la Cs es una cuestión de desarrollo tecnológico y de ética específica, dentro de los mecanismos institucionales competentes, nacionales e internacionales, para evaluar el desarrollo y la administración de los medicamentos. En conclusión, legalizar el uso de Cs para uso recreativo, enarbolando su uso medicinal, es una propuesta poco sustentada para el debate de su legalización y regulación.

\section{Despenalización de la portación para autoconsumo}

El Honorable Congreso de la Unión, a través del Congreso General de los Estados Unidos Mexicanos, con el fin de despenalizar la portación de algunas drogas de abuso, reformó la fracción XXIII del artículo 3, y parte de los subsecuentes artículos que la componen, en específico el artículo 479 de la Ley General de Salud (2009, pág. 6) que señala: "Para los efectos de este capítulo se entiende que el narcótico está destinado para su estricto e inmediato consumo personal, cuando la cantidad del mismo, en cualquiera de sus formas, derivados o preparaciones no exceda de las previstas en el listado siguiente":

Este decreto implica un avance porque se evitan la clandestinidad y la persecución de los usuarios. No obstante, la opción de despenalización de pequeñas cantidades de droga no se presenta como suficiente para evitar el crimen organizado, por la simple razón de que las organizaciones criminales no se detendrán y seguirán comercializando "productos" más redituables en relación a la Cs. Un estimado de 2016 (Elliott, 2016) indicó que el mercado negro internacional para los criminales, con intereses en las drogas duras, la trata de blancas y la venta de la vida silvestre, ronda entre los 70,000 y 213,000 millones de dólares anuales. Las ganancias que deja la mariguana, frente a drogas duras como la cocaína y la heroína es marginal, las organizaciones clandestinas no son eliminables por el simple artilugio de legalizar la Cs.

Una medida realmente radical contra el narcotráfico sería despenalizar la portación y el uso de todas las drogas de abuso sin atender el límite de la cantidad de portación para autoconsumo. Pero las políticas permisivas en el uso lúdico de la mariguana y de otras drogas de abuso no han tenido el éxito esperado, incluso en países considerados altamente desarrollados como Holanda (Freisthler \& Gruenewald, 2014; MacCoun, 2011; Salomonsen-Sautel, Sakai, Thurstone, Corley, \& Hopfer, 2012), donde la producción y la venta de casi cualquier droga de abuso han conllevado problemas sociales y de rendimiento en el trabajo (Velasco, 1997).

En fechas recientes, el ministro de Nueva Zelanda, John Key, lanzó un señalamiento a ciertos grupos antiinmigrantes en el sentido de que no se opusieran a la entrada de emigrantes al país para fortalecer las cadenas productivas, ya que no se puede producir con algunos ciudadanos del país, y apuntó: "carecen de una fuerte ética de trabajo y pueden tener problemas con las drogas", refiriéndose a la permisividad que hay ante el consumo de drogas en su país (ABC, 2016).

La legalización de la mariguana para fines recreativos conlleva riesgos de salud a escala epidémica, incluso en países que cuentan con sistemas políticos y de salud robustos. En los países considerados como desarrollados, la legalización de la mariguana no ha sido un avance, sino un retroceso en el desarrollo de los ciudadanos. En Holanda se partió de la falsa premisa de que "los jóvenes que consumen cantidades menores de mariguana no experimentarán después con otras drogas más peligrosas" (Velasco, 1997, p. 322). En México,

Tabla 1

Tabla de orientación de dosis máximas de consumo personal e inmediato

\begin{tabular}{lll}
\hline Narcótico & Dosis máxima de consumo personal e inmediato \\
\hline Opio & $2 \mathrm{gr}$ & \\
Diacetilmorfina o heroína & $50 \mathrm{mg}$ & \\
Cannabis sativa, índica o mariguana & $5 \mathrm{gr}$ & \\
Cocaína & $500 \mathrm{mg}$ & \\
Lisergida (LSD) & $0.015 \mathrm{mg}$ & Tabletas o cápsulas \\
MDA,metilendioxianfetamina & Polvo, granulado o cristal & Una unidad con peso no mayor a 200 mg \\
MDMA, & $40 \mathrm{mg}$ & Una unidad con peso no mayor a $200 \mathrm{mg}$ \\
dl-34-metilendioxi-n-dimetilfeniletilamina & $40 \mathrm{mg}$ & Una unidad con peso no mayor a 200 mg \\
Metanfetamina & $40 \mathrm{mg}$ &
\end{tabular}

Fuente: Ley General de Salud (2009). 
dada nuestra condición social, y los problemas inherentes a un país en desarrollo, la legalización de la mariguana para fines recreativos implicaría, por estricta disponibilidad, como ocurre con el alcohol, el establecimiento de condiciones sociales de riesgo. Se ha demostrado sobradamente que es la mariguana la sustancia de inicio para el uso de drogas más duras (Villatoro et al., 2016).

En un estudio longitudinal que realizaron Fergusson, Boden y Horwood (2006), en una cohorte de jóvenes entre los 14 y 25 años en Nueva Zelanda, encontraron que el consumo inicial de cannabis se asoció significativamente con el uso, el abuso y la dependencia de otras drogas ilícitas. Esta relación fue particularmente significativa durante la adolescencia. Wagner y Anthony (2002a) analizaron datos de cuatro muestras representativas e independientes de residentes en Estados Unidos $(n=44,624)$. Encontraron que el uso de cocaína se asocia con el consumo previo de mariguana; es decir que quienes la habían usado eran más propensos a consumir cocaína que aquellos sin antecedentes de uso de mariguana.

En un estudio que realizó López-Quintero et al. (2011) para identificar predictores sobre la probabilidad acumulada específica, general y racial-étnica en el desarrollo de dependencia en usuarios de nicotina, alcohol, mariguana y cocaína, se encontró que la estimación de probabilidad acumulada de la transición a la dependencia fue de $67.5 \%$ para usuarios de nicotina, $22.7 \%$ para consumidores de alcohol, 20.9\% para consumidores de cocaína y 8.9\% para usuarios de cannabis. La mitad de los casos de dependencia de nicotina, alcohol, cannabis y cocaína se observaron aproximadamente en 27,13 , cinco y cuatro años después de su uso inicial, respectivamente. La transición del uso a la dependencia fue más alta para los usuarios de nicotina, seguidos de los consumidores de cocaína, alcohol y cannabis. Estos resultados demostraron que la transición de la cannabis y la cocaína hacia la dependencia se produjo más rápido que la transición de la nicotina y el alcohol. Los autores sugirieron que el mayor riesgo de la transición a la dependencia, entre las personas pertenecientes a minorías o con comorbilidad psiquiátrica, resalta la importancia de promover la difusión y el tratamiento de estas poblaciones.

\section{Problemas de salud asociados con el uso de la mariguana}

Una revisión que realizaron Jain y Singh (2008), de 71 investigaciones, mostró que el uso de la mariguana tiene efectos del orden físico y mental. En otra revisión (Hall, 2009), que incluyó 89 estudios, se detectaron los principales efectos adversos para la salud del uso regular y sostenido de la cannabis. Entre los principales efec- tos adversos identificados se enumeraron: síndrome de dependencia, daño en la función respiratoria, enfermedades cardiovasculares, efectos en la salud mental y el desarrollo psicosocial del adolescente, y daño cognitivo residual.

Hall y Degenhardt (2009), en una revisión de 67 estudios, identificaron que la mariguana se relaciona con un mayor riesgo de accidentes automovilísticos, así como con el desarrollo de dependencia, deterioro de la función respiratoria, enfermedades cardiovasculares, síntomas psicóticos, efectos negativos en el desarrollo adolescente, menor rendimiento académico y mayor probabilidad de usar otras drogas ilícitas.

Bajo el auspicio del Proyecto Dunedin, del Multidisciplinary Health \& Development Research Unit en Nueva Zelandia, Arseneault, et al. (2002) realizaron un estudio de cohorte con 1037 individuos a los cuales se les dio seguimiento desde su nacimiento. Se hicieron mediciones psiquiátricas a los 26 años y se encontraron síntomas de esquizofrenia y depresión en esta población. En específico, los métodos de regresión lineal mostraron que los usuarios de cannabis que comenzaron entre los 15 y los 18 años de edad presentaban más síntomas de esquizofrenia que los sujetos control a los 26 años. Estos resultados se mantuvieron significativos al controlar los casos de psicóticos presentados a los 11 años.

También se encontró que los usuarios que iniciaron el uso cannabis a los 15 años eran cuatro veces más propensos a tener un diagnóstico de trastorno esquizofreniforme a los 26 años, que los participantes controles. El efecto fue mayor cuando los usuarios iniciaban a más temprana edad. En otro estudio con la misma línea de análisis, se vinculó el uso de mariguana y la emergencia de trastornos psiquiátricos (Arseneault, Cannon, Witton, \& Murray, 2004), aquí se indicó que la cannabis es un factor desencadenante de la esquizofrenia. Los autores identificaron que el consumo de esta droga precede a la aparición de esquizofrenia y que el uso de la misma en la adolescencia predispone a psicosis en la edad adulta.

Reece (2009) realizó una revisión sistemática de 5,198 artículos empíricos en los que se halló evidencia de que el uso de cannabis se asocia con problemas psiquiátricos importantes a largo plazo, incluyendo depresión, ansiedad, psicosis, trastorno bipolar y estado de desmotivación; con padecimientos respiratorios como reducción de la densidad pulmonar, quistes pulmonares y bronquitis crónica; con elevadas tasas de infarto de miocardio y arritmias cardiacas; afectaciones en el metabolismo óseo; y efectos teratogénicos en el cerebro en desarrollo después de la exposición perinatal. El cannabis se ha relacionado, asimismo, con cánceres en ocho sitios del cuerpo, y en niños expuestos durante el periodo de gestación. 


\section{Gestación y lactancia}

En un estudio documental, Garry et al. (2009), a partir de datos clínicos y farmacocinéticas, señaló que el uso de cannabis es de alto riesgo para el niño durante la lactancia materna: se observan sedación y reducción en el tono muscular; esto último también puede asociarse con el consumo de otras drogas o medicamentos como psicotrópicos o antiepilépticos. La evidencia sobre los efectos de la mariguana durante el embarazo, en particular en aquellas mujeres que habían consumido mariguana en la adolescencia o en la adultez temprana, reveló problemas en el desarrollo de los niños como fallas de la atención, funciones ejecutivas y trastornos de la conducta (Warner, Roussos-Ross, \& Behnke, 2014).

\section{Otros problemas de salud asociados con el uso de mariguana}

Los efectos fisiológicos de la mariguana incluyen taquicardia, broncodilatación, irritación conjuntival, reducción de lagrimeo natural y menor presión intraocular. Los efectos en el tracto respiratorio incluyen obstrucción pulmonar y carcinoma respiratorio; además, se generan cambios en la citología del tracto respiratorio, se aumenta el riesgo de sufrir los mismos trastornos asociados con el tabaco y se afectan las funciones pulmonares, como el flujo respiratorio. Además se identifica mutación celular a nivel pulmonar asociada con cáncer pulmonar. El sistema inmunológico también se ve afectado al actuar sobre la producción de linfocitos (Owen, Sutter, \& Albertson, 2014).

En un estudio que realizaron Aldington et al. (2008), con una muestra de 79 pacientes con cáncer de pulmón y 324 controles seleccionados de forma aleatoria, se encontró que el riesgo de padecer cáncer de pulmón, asociado con el uso de la mariguana, se incrementa $8 \%$ por cada año de consumo habitual de cannabis.

En un estudio donde se utilizó imagen por resonancia magnética de alta resolución para comparar la estructura cerebral (densidad y volumen de la materia gris y deformidad de las estructuras subcorticales) de un grupo de 20 adultos jóvenes (18-25 años) consumidores de mariguana versus 20 controles pareados por edad, sexo, años de estudio y lateralidad (no consumidores), no se hallaron diferencias significativas en el volumen de las estructuras, pero sí una significativa diferencia en la deformidad del lado derecho del núcleo accumbes y la amígdala de los consumidores, en comparación con los no consumidores (Giolman et al., 2014).

Se identificaron 1979 reportes de complicaciones cardiovasculares relacionadas con el uso de la mariguana, 35 fueron de consumidores exclusivos de esta droga.
Se encontraron 22 casos con complicaciones cardiacas, en especial síndromes coronarios; 10 de complicaciones periféricas como arteriopatías; y tres de complicaciones cerebrales como angiopatías y espasmos de las arterias cerebrales. Cabe señalar que nueve de las personas detectadas con cardiopatías fallecieron después de pocos meses (Jouanjus, Lapeyre-Mestre, \& Micallef, 2014).

Los efectos del uso crónico de la mariguana a nivel celular se asocian con reacciones alérgicas, afecciones al sistema inmune y modificaciones cromosomáticas. Se han detectado alteraciones cerebrales usando técnicas como electroencefalogramas; aumento de conductas agresivas; deterioro psicomotor; deficiencia en los sistemas de defensa de los macrófagos, que se relacionan con efectos cardiovasculares; toxicidad cardiaca; y baja producción hormonal, que afecta la fertilidad y la reproducción (Maykut, 1985).

A nivel celular también se han encontrado efectos por el uso de mariguana: Zalesky et al. (2012) evaluó la calidad de la fibra de las vías axonales como evidencia de alteraciones microestructurales del consumo crónico de mariguana. Se utilizaron imágenes de resonancia magnética de difusión ponderada y mapeos de conectividad cerebral en 59 consumidores exclusivos de mariguana versus 33 controles pareados. Se halló que en los usuarios la conectividad axonal se encontraba dañada del lado derecho del hipocampo, en el cuerpo calloso y en las fibras comisurales. Esto demostró que el uso de esta droga compromete la materia blanca del cerebro en desarrollo. Entre más tarde se inicie con el consumo de mariguana menos son los daños que se producen. Por esta razón, la población juvenil que usa mariguana es la que más riesgos de salud presenta.

\section{Trastornos de ajuste psicosocial}

Otros riesgos psicosociales asociados con el consumo son adicción tanto a la mariguana como a otras sustancias, menos logros a lo largo de la vida, accidentes en vehículos de motor, síntomas de bronquitis crónica. Con un nivel de confianza medio se registran desarrollo anormal del cerebro, progresión al uso de otras drogas, esquizofrenia, depresión o ansiedad (Volkow, Baler, Compton, \& Weiss, 2014).

En una encuesta transversal con 43 usuarios de mariguana se encontró que el uso de mariguana se relaciona con un aumento de la impulsividad y de conductas hostiles, así como con un incremento en la percepción de actitudes hostiles por parte terceros que conviven con los usuarios de mariguana (Ansell, Laws, Roche, \& Sinha, 2015). En un estudio prospectivo y longitudinal con 816 individuos y cinco mediciones, Brook, Lee, Finch, Seltzer y Brook (2013) compararon la tra- 
yectoria de abstinencia o de bajo nivel de consumo; identificaron que la trayectoria de consumo crónico de mariguana entre los 19 y 29 años constituye un predictor significativo de un mayor desempleo y una mayor inestabilidad económica en la vida adulta; igualmente, predice una mayor probabilidad de incapacidad laboral, problemas financieros y exposición a situaciones de violencia, entre otros factores.

En otro estudio longitudinal realizado en Nueva Zelanda con una cohorte de nacimiento de 1,265 sujetos, que fueron seguidos hasta los 25 años, se encontró que un mayor consumo de mariguana entre los 14 y 21 años se relaciona con un interés por estudiar hasta que se han cumplido los 25 años, un menor ingreso económico, una mayor dependencia del sistema de asistencia estatal, un mayor nivel de desempleo, más bajos niveles de satisfacción de vida y de las relaciones interpersonales. Estos resultados son estadísticamente significativos y muestran el efecto de la mariguana, pues se controló el efecto de otras variables o factores como el estrato socioeconómico, el ajuste familiar, el desempeño académico temprano y los trastornos mentales comórbidos, entre otros (Fergusson \& Boden, 2008).

En una revisión sistemática en la que se analizaron 56 estudios transversales y longitudinales se encontró una relación significativa entre el consumo de cannabis y una amplia gama de trastornos de ajuste escolar (bajo rendimiento escolar, baja satisfacción con el desarrollo escolar, actitudes negativas frente a la escuela, ausentismo). Los estudios prospectivo-longitudinales mostraron que el uso temprano de mariguana permite predecir significativamente un pobre desempeño académico y un mayor riesgo de abandono escolar (Lynskey \& Hall, 2000).

\section{Trayectoria de consumo y desarrollo de dependencia}

La popularidad del uso de los cannabinoides ha trascendido al uso de la mariguana en su estado natural, los derivados y los sintéticos de esta droga se han convertido en las sustancias ilícitas más utilizadas en los países desarrollados (Maldonado, Berrendero, Ozaita, \& Robledo, 2011). El uso de la mariguana tiene múltiples riesgos, tal como lo hemos documentado. Algunas de las opiniones populares acerca del consumo de esta droga afirman que no genera dependencia y que los usuarios pueden elegir racionalmente cuando dejar de consumirla, pero la evidencia científica muestra lo contrario.

Budney y Hughes (2006) reportaron que en 51 investigaciones empíricas se documentó síndrome de abstinencia clínicamente significativo, asociado con dependencia de mariguana, y que recurrentemente, las personas que solicitan apoyo clínico en instituciones de salud presentan el síndrome de abstinencia. Al respecto, Miller y Gold (1989) señalaron que la dependencia de mariguana implica tres indicadores críticos: 1) la preocupación por la adquisición de la mariguana, 2) su uso compulsivo y 3) la recaída o el uso recurrente de la droga. Agregaron que el uso agudo y crónico de la mariguana tiene consecuencias para los individuos en diferentes ámbitos como el médico, el psiquiátrico, el neurológico y el traumático, y provoca secuelas de convivencia en sociedad. En una encuesta representativa de una cohorte de población estadounidense de 15 a 54 años $(n=8,098)$, en la que se estudió comorbilidad (Wagner \& Anthony, 2002b), se encontró que $8 \%$ de los consumidores de mariguana desarrollaron dependencia en los 10 primeros años de consumo.

Un estudio que se realizó en Estados Unidos, en el cual se buscó identificar predictores sobre la probabilidad acumulada del desarrollo de dependencia de múltiples drogas, incluyó una submuestra de usuarios de cannabis $(7,389)$. Se encontró que la probabilidad acumulada de paso a la dependencia fue de $8.9 \%$ para los usuarios de cannabis; la mitad de los casos se registraron cinco años después del inicio de su consumo, lo que incluso es más rápido que la transición a la dependencia de nicotina y alcohol (López-Quintero et al., 2011). No obstante a los riesgos asociados con el consumo de mariguana, la investigación para prevenir y tratar su dependencia no se ha quedado estancada. La base neurobiológica para la retirada de cannabis se ha establecido a través del estudio e intervención del sistema cannabinoide endógeno, lo cual ha generado antagonistas de los receptores de cannabinoides. Los estudios de laboratorio han establecido la fiabilidad, la validez y la evolución a remisión del síndrome de abstinencia de cannabis; así pues, se ha comenzado a explorar el efecto de varios medicamentos en dicho retiro (Budney \& Hughes, 2006).

\section{DISCUSIÓN Y CONCLUSIONES}

La Cs es la droga ilícita más consumida a nivel mundial. Se calcula que 163 millones de personas la consumen en el mundo, esto representa a 3.9\% de la población total mayor de 15 años (Oficina de las Naciones Unidas contra la Droga y el Delito, 2003). Los usuarios que utilizan la mariguana con fines recreativos, por lo general inician su consumo en la adolescencia a una edad promedio de 17.4 años. En 2005, se reportó que la prevalencia a nivel mundial era de 2.1 millones de personas (Elkashef et al., 2008), cantidad que se refiere a los nuevos usuarios que se adhieren, al año, a la cifra de consumidores existentes. 
El uso de drogas, en general, incide principalmente en niños, adolescentes y adultos jóvenes pertenecientes a cualquier región y estrato social (Instituto Nacional de Psiquiatría Ramón de la Fuente Muñiz, Instituto Nacional de Salud Pública, \& Secretaría de Salud, 2012). Está comprobado que las drogas legales (alcohol y tabaco) y la Cs son las sustancias de inicio entre la juventud mundial, este mismo patrón se ha observado en México, donde la CS da pie al consumo de drogas más dañinas (duras), como la cocaína, las metanfetaminas y la heroína, por mencionar algunas. A lo anterior hay que agregar los siguientes aspectos que ponen en duda la legalización de la mariguana con fines lúdicos para combatir el narcotráfico en México:

1. El trasiego de la Cs no es el negocio principal del crimen organizado, en la jerga económica se puede decir que la cannabis es un producto elástico para las organizaciones criminales porque cuentan con productos más codiciados como la cocaína y la heroína, los cuales son más redituales. A la delincuencia no se le detiene legalizando una droga que les otorga poco rédito como la $\mathrm{Cs}$, al contrario, la legalización para fines recreativos facilitaría, a los grupos de narcotraficantes, el mercado de los potenciales consumidores de drogas duras. La delincuencia organizada, como toda organización lucrativa, busca la mayor cantidad de ganancias; los cárteles nacionales e internacionales se interesan más por el trasiego de cocaína, heroína, trata de personas, tráfico de personas y de vida silvestre. En pocas palabras, las organizaciones delictivas no cambian su estatus delincuencial, sólo migran sus intereses a nichos más redituables. Obviamente, el crimen organizado no tiene ética en sus negocios, se constituye por personas que no son fácilmente modificables. Una sociedad con poco o nulo narcotráfico se logra educando a la población mediante programas preventivos, establecidos de manera permanente, como el "Keepin' it REAL" (Kulis et al., 2005); paralelamente, es necesario ofrecerle medios de desarrollo que otorguen el estatus de ciudadanos funcionales a todos los miembros de la sociedad. En este sentido, el gobierno mexicano debe invertir en fortalecer la educación formal y en mejorar las oportunidades de desarrollo de la población, sobre todo de mujeres y niños, mediante la instrumentación de programas de asistencia social, a través de instituciones evaluadoras independientes y fortalecidas, como el Consejo Nacional de Evaluación de la Política de Desarrollo Social (CONEVAL).

2. Como se documentó anteriormente (Fergusson, Boden, \& Horwood, 2006; López-Quintero et al., 2011;
Wagner \& Anthony, 2002a), en tanto los jóvenes menores de edad sigan teniendo acceso a la mariguana con pocas trabas sociales, se incrementará su consumo, aun cuando se prohíba como ocurre con el alcohol y el tabaco. La disponibilidad de estas drogas, junto con la mariguana, es un detonante para que emerjan diversos problemas de salud como la depresión y las tendencias suicidas; dicha relación se ha encontrado en jóvenes mexicanos (Borges, Benjet, Orozco, Medina-Mora, \& Menéndez, 2017). Otros problemas, como los accidentes de tránsito, también pueden incrementarse (Asbridge, Hayden, \& Cartwringht, 2012).

3. Como se citó, el sistema nervioso de los jóvenes es más vulnerable al uso de la Cs que el de un adulto (Lubman et al., 2015); la Cs impide el aprendizaje a largo plazo por afectar una transmisión sináptica eficiente. El uso crónico de esta droga en edades tempranas afecta el almacenamiento, la retención y la revocación de eventos de aprendizaje (Battisti et al., 2010), por lo que impacta el rendimiento escolar e intelectual de los jóvenes en desarrollo. Esta deducción tiene implicaciones catastróficas para un país conformado principalmente por jóvenes, como la sociedad mexicana, en la que $50 \%$ de la población es menor de 30 años (Bush, 2010). Por lo tanto, en el país se requieren más oportunidades de desarrollo social y no de políticas permisivas para liberar indiscriminadamente el uso de la Cs. Un caso de éxito en medidas de atención social y de oportunidades de desarrollo comunitario y familiar para disminuir el uso de sustancias adictivas es Islandia (Sigfúsdóttir, Thorlindsson, Kristjánsson, Roe, \& Allegrante, 2008; Velleman, Templeton, \& Copello, 2005).

4. De permitirse la producción industrial de la mariguana con fines recreativos, se incrementará su uso en población mexicana por dos condiciones particulares inherentes a todo producto que se ofrece en el mercado: 1) la simple disponibilidad y 2) la creación de demanda, a través de la mercadotecnia formal e informal. Las características demográficas de la población expuesta a las farmacodependencias son uno de los temas a considerar en la legalización y regulación del uso lúdico de la mariguana. La legalización y la regulación de la mariguana en México es un tema complejo que tiene diferentes aristas e intereses. No obstante, es evidente que la mariguana tiene bastantes objeciones para que su uso lúdico sea viable en México. Estudios internacionales han mostrado que los países donde actualmente se regula la venta y uso de la mariguana para fines lúdicos y "médicos" no han 
solucionado el tema de las farmacodependencias, por ejemplo, en Estados Unidos se ha encontrado que la disponibilidad física de la mariguana medicinal mediante cafeterías o dispensarios ha incrementado su uso en la población, principalmente la juvenil (Freisthler \& Gruenewald, 2014). En Holanda, donde la mariguana se regula con fines medicinales, el consumo de la misma aumentó. Tanto así, que el consumo de cannabis en los jóvenes es más alto de lo que se esperaría en un mercado restringido (MacCoun, 2011). El incremento del uso de la mariguana "medicinal" en población adolescente aumentó en Denver, en una muestra de jóvenes con edades de entre 14 y 18 años. En esta población se encontró que $74 \%$ de ellos ya habían consumido mariguana "medicinal" (Salomonsen-Sautel et al., 2012). Tal como ocurre con el tabaco y el alcohol, la restricción para menores de edad no garantiza que no se use la sustancia; en cambio, la permisividad y la proliferación de dispensarios en la comunidad facilita su consumo.

En relación con este último señalamiento, en un estudio en el que se exploró la relación entre publicidad y el efecto en el consumo de la mariguana (D'Amico, Miles, \& Tucker, 2015), se entrevistó a jóvenes de secundaria en el sur de California $(n=8,214$,$) . 50 \%$ de ellos eran hombres; $52 \%$ hispanos, con una media de edad de 13 años. Se indagó la percepción de los adolescentes sobre el uso de mariguana, su exposición a publicidad de mariguana medicinal, su intención de uso y su consumo. Mediante un análisis de regresión, se encontró una asociación recíproca entre la exposición a la publicidad y las intenciones de uso y consumo: a mayor exposición a publicidad, una mayor probabilidad de consumo de mariguana y un mayor interés por utilizarla. Los autores sugirieron que en los programas de prevención se debería explicar lo que implica el uso de mariguana medicinal en el contexto de uso médico, y comentaron la necesidad de regular la publicidad de mariguana medicinal, como se hace con la del alcohol y el tabaco.

Con toda la evidencia citada y los argumentos expuestos durante esta revisión es indudable que la Cs tiene efectos devastadores sobre la salud humana. Concluimos que no hay país que resista una epidemia de adicciones; en México, en particular, la posibilidad de proveer a la población de mariguana con fines recreativos supone un riesgo a la salud pública, porque carecemos tanto de las condiciones sanitarias como de los profesionales necesarios para contrarrestar el flagelo de las farmacodependencias (Marín-Navarrete, Medina-Mora, \& Tena-Suck, 2016).

\section{REFERENCIAS}

ABC (2016, 7 de septiembre). El primer ministro de Nueva Zelanda dice que necesitan inmigrantes porque los neozelandeses son vagos y toman drogas. Recuperado de http://www.abc.es/ internacional/abci-primer-ministro-nueva-zelanda-dice-necesitan -inmigrantes-porque-neozelandeses-vagos-y-toman-drogas-20 1609061232_noticia.html

Alameda J., Paino, S., \& Mogedas, A. (2012). Toma de decisiones en consumidores de cannabis. Adicciones, 24(2), 161-172.

Aldington, S., Harwood, M., Cox, B., Weatherall, M., Beckert, L., Hansell, A., ... Beasley, R. (2008). Cannabis use and risk of lung cancer: a case-control study. European Respiratory Journal, 31(2), 280-286. doi: 10.1183/09031936.00065707

Ansell, E., Laws, H., Roche, M., \& Sinha, R. (2015). Effects of marijuana use on impulsivity and hostility in daily life. Drug and Alcohol Dependence, 148, 136-142. doi: 10.1016/j.drugalcdep. 2014.12.029

Arseneault, L., Cannon, M., Poulton, R., Murray, R., Caspi, A., \& Moffitt, T. (2002). Cannabis use in adolescence and risk for adult psychosis: longitudinal prospective study. British Medical Journal, 325(7374), 1212-1213.

Arseneault, L., Cannon, M., Witton, J., \& Murray, R. (2004). Causal association between cannabis and psychosis: examination of the evidence. The British Journal of Psychiatry, 184(2), 110-117.

Asbridge, M., Hayden, J., \& Cartwringht, J. (2012). Acute cannabis consumption and motor vehicle collision risk: systematic review of observational studies and meta-analysis. British Medical Journal, 344(e536), 1-9. doi: 10.1 136/bmj.e536

Balleine, B. W. (2005). Neural bases of food-seeking: affect, arousal and reward in corticostriatolimbic circuits. Physiology \& Behavior, 86(5), 717-730. doi: 10.1016/j.physbeh.2005.08.061

Battisti, R. A., Roodenrys, S., Johnstone, S. J., Respondek, C., Hermens, D. F., \& Solowij, N. (2010). Chronic use of cannabis and poor neural efficiency in verbal memory ability. Psychopharmacology, 209(4), 319-330. doi: 10.1007/s00213-010-1800-4

Beaulieu, P., Boulanger, A., Desroches, J., \& Clark, A. J. (2016). Medical cannabis: considerations for the anesthesiologist and pain physician. Canadian Journal of Anesthesia/Journal Canadien d'Anesthésie, 63(5), 608-624. doi: 10.1007/s12630-016-0598-x

Belrness, D., \& Porath-Waller, A. (2015). Clearing the smoke on cannabis. Cannabis use and driving-an update. Canada: Canadian Centre on Substance Abuse. Recuperado de http://www.cclt.ca/ Resource\%20Library/CCSA-Cannabis-Use-and-Driving-Report2015-en.pdf

Berridge, K., \& Robinson, T. (1998). What is the role of dopamine in reward: hedonic impact, reward learning, or incentive salience? Brain Research Reviews, 28(3), 309-369. doi:10.1016/s01650173(98)00019-8

Beverido, P. (2010). Consumo de mariguana y sus efectos en la salud mental y las habilidades cognitivas necesarias para el aprendizaje. Revista Médica Universidad Veracruzana. 10(2), 49-53. 
Birdsall, S. M., Birdsall, T. C., \& Tims, L. A. (2016). The use of medical marijuana in cancer. Current Oncology Reports, 18(7), 1-9. doi: 10.1007/s11912-016-0530-0

Bolla, K. I., Brown, K., Eldreth, D., Tate, K., \& Cadet, J. (2002). Dose-related neurocognitive effects of marijuana use. Neurology, 59(9), 1337-1343. doi:10.1212/01.wnl.0000031422.66442.49

Borges, G., Benjet, C., Orozco, R., Medina-Mora, M. E., \& Menéndez, D. (2017). Alcohol, cannabis and other drugs and subsequent suicide ideation and attempt among young Mexicans. Journal of Psychiatric Research, 91, 74-82. doi: 10.1016/j.jpsychires.2017.02.025

Brady, J., \& Li, G. (2014). Trends in alcohol and other drugs detected in fatally injured drivers in the United States, 1999-2010. American Journal of Epidemiology, 179(6), 692-699. doi: 10.1093/aje/kwt327

Brook, J., Lee, J., Finch, S., Seltzer, N., \& Brook, D. (2013). Adult work commitment, financial stability, and social environment as related to trajectories of marijuana use beginning in adolescence. Substance Abuse, 34(3), 298-305. doi: 10.1080/08897077.2013.775092

Budney, A. J., \& Hughes, J. R. (2006). The cannabis withdrawal syndrome. Current Opinion Psychiatry, 19(3), 233-238. doi:10.1097/01. yco.0000218592.00689.e5

Bunge, M. A. (1979). Treatise on basic philosophy. Ontology II: a world of systems. Londres: D. Reidel Publishing Company.

Bush, V. P. (2010). Proyecciones de la población de México 20052050. México: CONAPO.

Cota, D., Tschöp, M. H., Horvath, T. L., \& Levine, A. S. (2006). Cannabinoids, opioids and eating behavior: The molecular face of hedonism? Brain Research Reviews, 51(1), 85-107. doi: 10.1016/j.brainresrev.2005.10.004

Citri, A., \& Malenka, R. C. (2008). Synaptic plasticity: multiple forms, functions and mechanisms. Neuropsychopharmacology, 33(1), 18-41. doi: 10.1038/sj.npp.1301559

Cotter, J. (2009). Efficacy of crude marijuana and synthetic Delta-9-Tetrahydrocannabinol as treatment for chemotherapy-induced nausea and vomiting: a systematic literature review. Oncology Nursing Forum, 36(3), 345-352. doi: 10.1188/09.onf.345-352

Crancer, A., \& Crancer, A. (2010). The involvement of marijuana in California fatal motor vehicle crashes 1998-2008 (working paper). California: Institute for Behavior and Health, Inc. Recuperado de http://truecompassion.org/PDFS/Drugged\%20Driving/ CA\%20MJ\%20Study\%20The\%20involvement\%20of\%20mj\%20 in\%20fatal\%20car\%20accidents.pdf

Crane, N. A., Schuster, R. M., Fusar-Poli, P., \& Gonzalez, R. (2012). Effects of cannabis on neurocognitive functioning: recent advances, neurodevelopmental influences and sex differences. Neuropsycholgy Review, 23(2), 117-137. doi: 10.1007/s11065012-9222-1

D’Amico, E. J., Miles, J. N. V., \& Tucker, J. S. (2015). Gateway to curiosity: medical marijuana ads and intention and use during middle school. Psychology of Addictive Behaviors, 29(3), 613619. doi: $10.1037 / \mathrm{adb} 0000094$

Deadwyler, S. A., \& Hampson, R. E. (2008). Endocannabinoids modulate encoding of sequential memory in the rat hippocampus.
Psychopharmacology, 198(4), 577-586. doi:10.1007/s00213-007 $-1055-x$

Degenhardt, L., \& Hall, W. (2002). Cannabis and psychosis. Current Psychiatry Reports, 4(3), 191-196. doi: 10.1007/s11920-002-0026-5

Degenhardt, L., \& Hall, W. (2006). Is cannabis use a contributory cause of psychosis? Canadian Journal of Psychiatry, 51(9), 556565. doi: 10.1177/070674370605100903

Degenhardt, L., Coffey, C., Romaniuk, H., Swift, W., Carlin, J., Hall, W., ... Patton, G. (2013). The persistence of the association between adolescent cannabis use and common mental disorders into young adulthood. Addiction, 108(1), 124-133. doi: 10.1111/j.1360-0443.2012.04015.x

Degenhardt, L., Hall, W., \& Lynskey, M. (2003). Exploring the association between cannabis use and depression. Addiction 98(11), 1493-1504. doi:10.1046/j.1360-0443.2003.00437.x

Elkashef, A., Vocci, F., Huestis, M., Haney, M., Budney, A., Gruber, A., \& el-Guebaly, N. (2008). Marijuana neurobiology and treatment. Substance Abuse, 29(3), 17-29. doi:10.1080/0889707080 2218166

Elliott, L. (2016). Criminal networks and black markets in transnational environmental crime, in toine spapens. Rob White, \& Wim Huisman (ed.). Environmental crime in transnational context: global issues in green enforcement and criminology (pp. 233249). Abingdon, Oxon: Routledge Taylor \& Francis Group

Fergusson, D., \& Boden, J. (2008). Cannabis use and later life outcomes. Addiction, 103(6), 969-976. doi: 10.1111/j.1360-0443. 2008.02221.x

Fergusson, D. M., Boden, J. M., \& Horwood, L. J. (2006). Cannabis use and other illicit drug use: testing the cannabis gateway hypothesis. Addiction, 101(4), 556-569. doi: 10.1111/j.13600443.2005.01322.x

Filbey, F., Aslan, S., Calhoun, V., Spence, J., Damaraju, E., Caprihan, A., ... Segall, J. (2014). Long-term effects of marijuana use on the brain. Proceedings of the National Academy of Sciences, 111(47), 16913-16918. Recuperado de www.pnas.org/cgi/ doi/10.1073/pnas.1415297111

Fogarty, A., Rawstorne, P., Prestage, G., Crawford, J., Grierson, J., \& Kippax, S. (2007). Marijuana as therapy for people living with HIVIAIDS: social and health aspects. AIDS Care, 19(2), 295-301. doi:10.1080/09540120600841930

Freisthler, B., \& Gruenewald, P. (2014). Examining the relationship between the physical availability of medical marijuana and marijuana use across fifty California cities. Drug and Alcohol Dependence, 143, 244-250. doi: 10.1016/j.drugalcdep.2014.07.036

Freund, T. F., Katona, I., \& Piomelli, D. (2003). Role of endogenous cannabinoids in synaptic signaling. Physiological Reviews, 83(3), 1017-1066. doi: 10.1152/physrev.00004.2003

Fried, P., Watkinson, B., James, D., \& Gray, R. (2002). Current and former marijuana use: preliminary findings of a longitudinal study of effects on IQ in young adults. Canadian Medical Association Journal, 166(7), 887-891.

Garfield, J. B. B., Lubman, D. I., \& Yücel, M. (2013). Anhedonia in substance use disorders: a systematic review of its nature, cour- 
se and clinical correlates. Australian \& New Zealand Journal of Psychiatry, 48(1), 36-51. doi:10.1177/0004867413508455

Garry, A., Rigourd, V., Amirouche, A., Fauroux, V., Aubry, S., \& Serreau, R. (2009). Cannabis and breastfeeding. Journal of Toxicology, 2009, 1-5. doi:10.1155/2009/596149

Gerdeman, G. L., \& Lovinger, D. M. (2003). Emerging roles for endocannabinoids in long-term synaptic plasticity. British Journal of Pharmacology, 14O(5), 781-789. doi: 10.1038/sj.bjp.0705466

Gilman, J. M., Kuster, J. K., Lee, S., Lee, M. J., Kim, B. W., Makris, N., ... Breiter, H. C. (2014). Cannabis use is quantitatively associated with nucleus accumbes and amygdala abnormalities in young adult recreational users. The Journal of Neuroscience, 34(16), 5529-5538. doi: 10.1523/jneurosci.4745-13.2014

Hall, W. (2009). The adverse effects of cannabis use. What are they and what are their implications for policy? International Journal of Drug Policy, 20(6), 458-466. doi: 10.1016/j.drugpo.2009.02.013

Hall, W., \& Degenhardt, L. (2009). Adverse health effects of non-medical cannabis use. The Lancet, 374(9698), 1383-1391. doi:10.1016/s0140-6736(09)61037-0

Hall, W., Degenhardt, L., \& Teesson, M. (2004). Cannabis use and psychotic disorders: an update. Drug and Alcohol Review, 23(4), 433-443. doi: 10.1080/09595230412331324554

Hanson, K. L., Winward, J. L., Schweinsburg, A. D., Medina, K. L., Brown, S. A., \& Tapert, S. (2010). Longitudinal study of cognition among adolescent marijuana users over three weeks of abstinence. Addictive Behaviours, 35(11), 970-976. doi: 10.1016/j. addbeh.2010.06.012

Hart, C. L., Ward, A. S., Haney, M., Comer, S. D., Foltin, R. W., \& Fischman, M. W. (2002). Comparison of smoked marijuana and oral $\Delta$-tetrahydrocannabinol in humans. Psychopharmacology, 164(4), 407-415. doi:10.1007/s00213-002-1231-y

Hebert-Chatelain, E., Desprez, T., Serrat, R., Bellocchio, L., Soria-Gomez, E., Busquets-Garcia, A., ... Marsicano, G. (2016). A cannabinoid link between mitochondria and memory. Nature, 539(7630), 555-559. doi:10.1038/nature20127

Hurd, Y. L., Michaelides, M., Miller, M. L., \& Jutras-Aswad, D. (2014). Trajectory of adolescent cannabis use on addiction vulnerability. Neuropharmacology, 76, 416-424. doi:10.1016/j.neuropharm. 2013.07.028

Instituto Nacional de Psiquiatría Ramón de la Fuente Muñiz, Instituto Nacional de Salud Pública, \& Secretaría de Salud. (2012). Encuesta Nacional de Adicciones 2011: Reporte de Drogas. ViIlatoro-Velázquez, J. A., Medina-Mora, M. E., Fleiz-Bautista, C., Téllez-Rojo, M. M., Mendoza-Alvarado, L. R., Romero-Martínez, M.,... Guisa-Cruz, V. México: INPRFM.

Iversen, L. (2003). Cannabis and the brain. Brain, 126(6), 12521270. doi: 10.1093/brain/awg143

Jain, R., \& Singh, Y. (2008). Neurobiology of cannabis addiction. Indian Journal of Physiological Pharmacology, 52(3), 217-232.

Ji, T. H., Grossmann, M., \& Ji, I. (1998). G protein-coupled receptors. Diversity of receptor-ligand interactions. Journal of Biological Chemistry, 273(28), 17299-17302. doi: 10.1074/ jbc.273.28.17299
Jouanjus, E., Lapeyre-Mestre, M., \& Micallef, J. (2014). Cannabis use: signal of increasing risk of serious cardiovascular disorders. Journal of the American Hearth Association, 32(2) 1-7 doi:10.1161/jaha.113.000638

Justinova, Z., Goldberg, S. R., Heishman, S. J., \& Tanda, G. (2005). Self administration of cannabinoids by experimental animals and human marijuana smokers. Pharmacology Biochemistry and Behavior, 81(2), 285-299. doi: 10.1016/j.pbb.2005.01.026

Katona, I., \& Freund, T. F. (2008). Endocannabinoid signaling as a synaptic circuit breaker in neurological disease. Nature Medicine, 14(9), 923-930. doi: 10.1038/nm.f.1869

Kowal, M. A., Hazekamp, A., Colzato, L. S., van Steenbergen, H., van der Wee, N. J. A., Durieux, J., ... Hommel, B. (2015). Cannabis and creativity: highly potent cannabis impairs divergent thinking in regular cannabis users. Psychopharmacology, 232(6), 1123-1134. doi: 10.1007/s00213-014-3749-1

Kruk-Slomka, M., \& Biala, G. (2016). CB1 receptors in the formation of the different phases of memory-related processes in the inhibitory avoidance test in mice. Behavioral Brain Research, 301, 84-95. doi: 10.1016/j.bbr.2015.12.023

Kulis, S., Marsiglia, F. F., Elek, E., Dustman, P. A., Wagstaff, D. A., \& Hecht, M. L. (2005). Mexican/Mexican American adolescents and Keepin' it REAL: an evidence-based substance use prevention program. Children and Schools, 27(3), 133-145. doi. org/10.1093/cs/27.3.133

Large, M., Sharma, S., Compton, M., Slade, T., \& Nielssen, O. (2011). Cannabis use and earlier onset of psychosis: a systematic meta-analysis. Archives of General Psychiatry, 68(6), 555-561. doi: 10.1001/archgenpsychiatry.2011.5

Laumon, B., Gadegbeku, B., Martin, J. L., \& Biecheler, M. B. (2005). Cannabis intoxication and fatal road crashes in France: population based case-study. British Medical Journal, 331(7529), 1-6 doi: 10.1136/bmj.38648.617986.1F

Leleu-Chavain, N., Desreumaux, P., Chavatte, P., \& Millet, R. (2014). Therapeutical potential of CB2 receptors in immune-related diseases. Current Molecular Pharmacology, 6(3), 183-203. doi: 10.2174/1874467207666140219122337

Lev-Ran, S., Roerecke, M., Le Foll, B., George, T. P., McKenzie, K., \& Rehm, J. (2013). The association between cannabis use and depression: a systematic review and meta-analysis of longitudinal studies. Psychological Medicine, 44(04), 797-810. doi: 10.1017/s0033291713001438

Ley General de Salud. (2009). Decreto por el que se reforman, adicionan y derogan diversas disposiciones de la Ley General de Salud, del Código Penal Federal y del Código Federal de Procedimientos Penales. México. Recuperado de http://dof.gob.mx/ nota_detalle_popup.php?codigo $=5106093$.

López-Quintero, C., Pérez de los Cobos, J., Hasin, D., Okuda, M., Wang, S., Grant, B., ... Blanco, C. (2011). Probability and predictors of transition from first use to dependence on nicotine, alcohol, cannabis, and cocaine: results of the National Epidemiologic Survey on Alcohol and Related Conditions (NESARC). Drug and Alcohol Dependence, 115(1-2), 120-130. doi: 10.1016/j.drugalcdep.2010.11.004 
Lorenzetti, V., Solowij, N., Whittle, S., Fornito, A., Lubman, D. I., Pantelis, C., \& Yücel, M. (2015). Gross morphological brain changes with chronic, heavy cannabis use. The British Journal of Psychiatry, 206(1), 77-78. doi: 10.1192/bjp.bp.114.151407

Lubman, D. I., Cheetham, A., \& Yücel, M. (2015). Cannabis and adolescent brain development. Pharmacology \& Therapeutics, 148, 1-16. doi: 10.1016/.j.pharmthera.2014.11.009

Lupica, C. R., Riegel, A. C., \& Hoffman, A. F. (2004). Marijuana and cannabinoid regulation of brain reward circuits. British Journal of Pharmacology, 143(2), 227-234. doi: 10.1038/sj.bjp.0705931

Lynskey, M., \& Hall, W. (2000). The effects of adolescent cannabis use on educational attainment: a review. Addiction, 95(11), 1621-1630. doi: 10.1046/j.1360-0443.2000.951116213.x

MacCoun, R. J. (2011). What can we learn from the Dutch cannabis coffeeshop system? Addiction, 106(11), 1899-1910. doi: 10.1111/j.1360-0443.2011.03572.x

Maldonado, R., Berrendero, F., Ozaita, A., \& Robledo, P. (2011). Neurochemical basis of cannabis addiction. Neuroscience, 181, 1-17. doi: 10.1016/j.neuroscience.2011.02.035

Malinow, R., Mainen, Z. F., \& Hayashi, Y. (2000). LTP mechanisms: from silence to four-lane traffic. Current Opinion in Neurobiology, 10(3), 352-357. doi: 10.1016/s0959-4388(00)00099-4

Marín-Navarrete, R., Medina-Mora, M. E., \& Tena-Suck, A. (2016). Addiction care in Mexico: a challenge for non-specialized health professionals. Salud Mental, 39(5), 241-242. doi: 10.17711/ sm.0185-3325.2016.027

Marsicano, G., \& Lafenêtre, P. (2009). Roles of the endocannabinoid system in learning and memory. En Behavioral Neurobiology of the Endocannabinoid System (pp. 201-230). Berlín: Springer Berlin Heidelberg.

Matsuda, L. A., Lolait, S. J., Brownstein, M. J., Young, A. C., \& Bonner, T. I. (1990). Structure of a cannabinoid receptor and functional expression of the cloned cDNA. Nature, 346(6284), 561-564. doi: $10.1038 / 346561 \mathrm{a0}$

Maykut, M. O. (1985). Health consequences of acute and chronic marijuana users. Progress in Neuro-Psychomacology and Biological Psychiatry, 9(3), 209-238. doi:10.1016/0278-5846(85) 90085-5

Meier, M. H., Caspi, A., Ambler, A., Harrington, H., Houts, R., Keefe, R. S. E., ... Moffitt, T. E. (2012). Persistent cannabis users show neuropsychological decline from childhood to midlife. Proceedings of the National Academy of Sciences. 109(40), E2657-E2664. doi: 10.1073/pnas.1206820109

Mena, I., Dörr, A., Viani, S., Neubauer, S., Gorostegui, M., Dörr, P., \& Ullca, D. (2013). Efectos del consumo de la marihuana en escolares sobre funciones cerebrales demostrados mediante pruebas neuropsicológicas e imágenes de neuro-SPECT. Salud Mental, 36(5), 367-374. doi: 10.17711/sm.0185-3325.2013.045

Miller, N., \& Gold, M. (1989). The diagnosis of marijuana (cannabis) dependence. Journal of Substance Abuse Treatment, 6(3), 183192. doi: 10.1016/0740-5472(89)90005-6

Moore, T. H., Zammit, S., Lingford-Hughes, A., Barnes, T. R., Jones, P. B., Burke, M., \& Lewis, G. (2007). Cannabis use and risk of psychotic or affective mental health outcomes: a systematic review. The Lancet, 370(9584), 319-328. doi: 10.1016/s01406736(07)61162-3

Munro, S., Thomas, K. L., \& Abu-Shaar, M. (1993). Molecular characterization of a peripheral receptor for cannabinoids. Nature, 365(6441), 61-65. doi: 10.1038/365061a0

Nielsen, S., Germanos, R., Weier, M., Pollard, J., Degenhardt, L., Hall, W., ... Farrell, M. (2018). The use of cannabis and cannabinoids in treating symptoms of multiple sclerosis: a systematic review of reviews. Current Neurology and Neuroscience Reports, 18(2), 1-12. doi: 10.1007/s11910-018-0814-x

Oficina de las Naciones Unidas contra la Droga y el Delito. (2003). Global illicit drug trends. Vienna, Austria: United Nations International Drug Control Programme Research Section.

Owen, K. P., Sutter, M. E., \& Albertson, T. E. (2013). Marijuana: respiratory tract effects. Clinical Reviews in Allergy and Immunology, 46(1), 65-81. doi: 10.1007/s12016-013-8374-y

Patton, G., Coffey, C., Carlin, J., Degenhardt, L., Lynskey, M., \& Hall, W. (2002). Cannabis use and mental health in young people: cohort study. British Medical Journal, 325(7374), 1195-1198. doi: 10.1136/bmj.325.7374.1195

Pertwee, R. G. (1997). Pharmacology of cannabinoid CB1 and CB2 receptors. Pharmacology \& Therapeutics, 74(2), 129-180. doi: 10.1016/s0163-7258(97)82001-3

Pertwee, R. G. (2006). The pharmacology of cannabinoid receptors and their ligands: an overview. International Journal of Obesity, 30(S1), s13-s18. doi: 10.1038/sj.ijo.0803272

Piomelli, D. (2003). The molecular logic of endocannabinoid signalling. Nature Reviews, Neuroscience, 4(11), 873-884. doi 10.1038/nrn1247

Pope, H. G., Gruber, A. J., Hudson, J. I., Huestis, M. A., \& Yurgelum-Todd, D. (2001). Neuropsychological performance in longterm cannabis users. Archives of General Psychiatry, 58(10), 909-915. doi: 10.1001/archpsyc.58.10.909

Reece, A. S. (2009). Chronic toxicology of cannabis. Clinical Toxicology, 47(6), 517-524. doi: 10.108/15563650903074507

Robinson, L., McKillop-Smith, S., Ross, N. L., Pertwee, R. G., Hampson, R. E., Platt, B., ... Riedel, G. (2007). Hippocampal endocannabinoids inhibit spatial learning and limit spatial memory in rats. Psychopharmacology, 198(4), 551-563. doi: 10.1007/ s00213-007-1012-8

Salomonsen-Sautel, S., Min, S., Sakai, J., Thurstone, C. \& Hopfer, C. (2014). Trends in fatal motor vehicle crashes before and after marijuana commercialization in Colorado. Drug Alcohol Dependence, 140, 137-144. doi: 10.1016/j.drugalcdep.2014.04.008

Salomonsen-Sautel, S., Sakai, J., Thurstone, C., Corley, R., \& Hopfer, C. (2012). Medical marijuana use among adolescents in substance abuse treatment. Journal of the American Academy of Child \& Adolescent Psychiatry, 51(7), 694-702. doi: 10.1016/j. jaac.2012.04.004

Secretaría de Salud. (2017). Decreto por el que se reforman y adicionan diversas disposiciones de la Ley General de Salud y del Código Penal Federal. Reforma 107: Ley General de Salud. 
Diario Oficial de la Federación. (DOF 19-06-2017). Recuperado de www.diputados.gob.mx/LeyesBiblio/ref/lgs/LGS_ref107_ 19jun17.doc

Secretaría de Gobernación. (2016). Relatoría del debate nacional sobre el uso de la mariguana. México: Segob, SSa. Recuperado de http://framework-gb.cdn.gob.mx/data/420/RELATORIA_ DEBATE_NAL_USO_MARIGUANA_PRELIMINAR.pdf.

Semple, D., Mclntosh, A., \& Lawrie, S. (2005). Cannabis as a risk factor for psychosis: systematic review. Journal of Psychopharmacology, 19(2), 187-194. doi: 10.1177/0269881105049040

Sigfúsdóttir, I. D., Thorlindsson, T., Kristjánsson, A. L., Roe, K. M., \& Allegrante, J. P. (2008). Substance use prevention for adolescents: the Icelandic model. Health Promotion International, 24(1), 16-25. doi:10.1093/heapro/dan038

Simons, J., Clarke, J., Simons, R., \& Spelman, P. (2016). Marijuana consequences in a motivational context: goal congruence reduces likelihood of taking steps toward change. Addictive Behaviors, 52, 83-90. doi: 10.1016/j.addbeh.2015.08.010

Sullivan, J. M. (2000). Cellular and molecular mechanisms underlying learning and memory impairments produced by cannabinoids. Learning \& Memory, 7(3), 132-139. doi: 10.1101/Im.7.3.132

Szabo, B., Siemes, S., \& Wallmichrath, I. (2002). Short communication. Inhibition of GABAergic neurotransmission in the ventral tegmental area by cannabinoids. European Journal of Neuroscience, 15(12), 2057-2061. doi: 10.1046/j.1460-9568.2002.02041.x

Tapert, S., Schweinsburg, A., \& Brown, S. (2008). The influence of marijuana use on neurocognitive functioning in adolescents. $\mathrm{Cu}$ rrent Drug Abuse Reviews, 1(1), 99-111. doi: 10.2174/18744737 10801010099

Tebano, M. T., Martire, A., \& Popoli, P. (2012). Adenosine A 2A-cannabinoid CB1 receptor interaction: an integrative mechanism in striatal glutamatergic neurotransmission. Brain Research, 1476, 108-118. doi: 10.1016/j.brainres.2012.04.051

Van Os, J., Bak, M., Hanssen, M., Bijl, R., de Graaf, R., \& Verdoux, H. (2002). Cannabis use and psychosis: a longitudinal population-based study. American Journal of Epidemiology, 156(4), 319-327. doi: 10.1093/aje/kwf043

Velasco, R. (1997). El problema de la farmacodependencia. En Ramón de la Fuente (Coord.). La patología mental y su terapéutica II. México: Fondo de Cultura Económica.

Velázquez, J. A., Icaza, M. E., Sánchez, R., Ito, D. A., ... Gamiño, M. N. (2016). El consumo de drogas en estudiantes de México: tendencias y magnitud del problema. Salud Mental, 39(4), 193-203. doi:10.17711/sm.0185-3325.2016.023

Vélez, A., Borja, K., \& Ostrosky-Solís, F. (2010). Efectos del consumo de marihuana sobre la toma de decisión. Revista Mexicana de Psicología, 27(2), 309-315.
Velleman, R. D., Templeton, L. J., \& Copello, A. G. (2005). The role of the family in preventing and intervening with substance use and misuse: a comprehensive review of family interventions, with a focus on young people. Drug and Alcohol Review, 24(2), 93109. doi: 10.1080/09595230500167478

Verdejo-García, A. (2011). Efectos neuropsicológicos del consumo de cannabis. Trastornos adictivos, 13(03), 97-101. doi:10.1016/ s1575-0973(11)70021-6

Villanueva, C. (2010). Los pros y los contras del uso de la mariguana. Cuicuilco, 17(49), 13-30.

Volkow, N. D., Baler, R. D., Compton, W. M., \& Weiss, S. R. B. (2014). Adverse health effects of marijuana use. New England Journal of Medicine, 370(23), 2219-2227. doi: 10.1056/nejmra1402309

Wagner, F., \& Anthony, J. (2002a). Into the world of illegal drug use: exposure opportunity and other mechanisms linking the use of alcohol, tobacco, marijuana, and cocaine. American Journal of Epidemiology, 155(10), 918-925. doi: 10.1093/aje/155.10.918

Wagner, F., \& Anthony, J. (2002b). From first drug use to drug dependence: developmental periods of risk for dependence upon marijuana, cocaine, and alcohol. Neuropsychopharmacology, 26(4), 479-488. doi: 10.1016/s0893-133x(01)00367-0

Warner, T., Roussos-Ross, D., \& Behnke, M. (2014). It's not your mother's marijuana: effects on maternal-fetal health and developing child. Clinics of Perinatology, 41, 877-894. doi: 10.1016/j. clp.2014.08.009

Whiting, P. F., Wolff, R. F., Deshpande, S., Di Nisio, M., Duffy, S., Hernandez, A. V., ... Kleijnen, J. (2015). Cannabinoids for medical use: a systematic review and meta-analysis. Journal of the American Medical Association (JAMA), 313(24), 2456-2473. doi: 10.1001/jama.2015.6358

Yamamoto, I., Watanabe, K., Matsunaga, T., Kimura ,T., Funahashi, T., \& Yoshimura, H. (2003). Pharmacology and toxicology of major constituents of marijuana - on the metabolic activation of cannabinoids and its mechanism. Journal of Toxicology: Toxin Reviews, 22(4), 577-589. doi: 10.1081/txr-120026915

Yeomans, M. R., \& Gray, R. W. (2002). Opioid peptides and the control of human ingestive behaviour. Neuroscience and Biobehavioral Reviews, 26(6), 713-128. doi: 10.1016/s0149-7634(02)00041-6

Zalesky, A., Solowij, N., Yücel, M., Lubman, D., Takagi, M., Harding, I., ... Seal, M. (2012). Effect of long-term cannabis use on axonal fibre connectivity. Brain, 135(7), 2245-2255. doi: 10.1093/brain/ aws 136

Zammit, S. Moore, T., Lingford-Hughes, A., Barnes, T., Jones, P., Burke, M., ... Lewis, G. (2008). Effects of cannabis use on outcomes of psychotic disorders: Systematic review. British Journal of Psychiatry, 193(5) 357-363. doi: 10.1192/bjp.bp.107.046375 